\title{
INVESTIGATING THE ROLE OF MANAGER'S ATTITUDE FOR THE PERFORMANCE OF SUBORDINATES: A STUDY FOR COMPARISON BETWEEN BOSS AND A LEADER
}

\author{
Syed Waleed Warsi1 \\ Institute of Business \& Technology, Karachi \\ Ghulam Mustafa2 \\ Institute of Business \& Technology, Karachi \\ Saeed Ahmed3 \\ Institute of Business \& Technology, Karachi
}

\begin{abstract}
Purpose: This study examines the perception of the subordinates about their Bosses. The objective of this research is to test whether the Boss is always right in respect of his or her behavior, attitude, dealing with subordinates and ethical considerations. Methodology: A well designed questionnaire based on Licker scale has been used to conduct a comprehensive from the professionals from various companies in Pakistan including Banking, Financial Firms and Manufacturing Companies. The study considers the applications of OLS estimation and descriptive analysis for empirical evidences. Findings: The findings of this study suggest that Manager as Leader has positive and supportive role in organizational success. The respondent has agreed that their Manager as Leader behaves with positive attitude, fulfill ethical consideration and makes judgment impartially. The respondents Believe that their Manager as Leader usually response to them with positive and supportive attitude which help them in achieving their objectives. The respondents show their consent that behavior of their Manager as Leader is impartial and unbiased during conflict resolution and submission of recommendation for evaluation. Further, it also has been concluded that Manager as Leader prefer organizational objectives over their personal objectives and their Manager as Leader do not force them to do any unethical deed to benefit them. Lastly, the Manager as Leader also appreciates the innovative ideas of the subordinates.

Practical Implication: This study suggests that performance of employee can be increased via leadership attitude of manager, whereas, the employees are not satisfied with traditional or boss type attitude of a manager. This study recommends a supportive leadership style for the managers.
\end{abstract}

\section{Key terms: Boss, Supervisor, Leader}

\footnotetext{
* The material presented by the author does not necessarily portray the viewpoint of the editors and the management of the Institute of Business \& Technology (IBT)

${ }_{2}^{1}$ Syed Waleed Warsi

2 Ghulam Mustafa

:waleed.warsi@ibt.edu.pk

${ }^{3}$ Saeed Ahmed

:iu.gmshaikh@gmail.com

:saeedgaad@gmail.com

(C) IBT-JBS is published by the Institute of Business and Technology (IBT).

Main Ibrahim Hydri Road, Korangi Creek, Karachi-75190, Pakistan.
} 


\section{INTRODUCTION \\ 1.1 Overview}

The role and perception about the Boss has always remained a matter of debate in organizational environments. Usually employees do complain about the dictatorial behavior of their Bosses, however, sometimes the broad vision of the Bosses has also been appreciated. Many studies have been made on the subject of role and perception about the leadership styles and actual and imaginary perception about the leader or the Boss in an organization. Some studies discusses about relationship of leadership role of a Boss and company's performance. There are several studies discussing the motivational role of a manager or so called Boss.

However, there is very small literature available discussing the practical perception about the Boss. This study is aimed at analyzing whether always Boss is Right. The scope of our study includes the perception of employees about the attitude of their Boss and the result of such attitude over the performance of subordinates as well as on over all organizational objectives. The attitude of a Boss plays vital role in developing organizational environment, therefore, professional attitude of a Boss may develop a professional in an organization. In addition to it, the perception of employee's about the ethical consideration of Boss shall also be analyzed. The ethical issues are essential for creating strong organizational culture as well as organizational values. Every organization has to set its ethical standard so to create and build positive perception about the organization in external environment. The issues of favoritism and biasness are also very important to discuss regarding the Boss. Favoritism and Biasness creates aggressive political environment, where employees develop empire building against each other. Therefore, an Ideal Boss should have to avoid favoritism and Biasness. Finally, the broad vision of a Boss may be observed with how he or she supports the innovative ideas of his or her subordinates. An ideal Boss always supports and encourages the innovative ideas and creativity of his or her subordinates.

On the other side, Kaityan (2011) investigated the perception of employees' loyality. Conclusion suggests that Loyalty is very vital because lack of this element can create decline in productivity and increase in turnover. The study of Brusman (2009)is also very interesting, it suggests that when one is promoted to higher level it is very necessary to change the bad habits. After a time it is very necessary for us to accept change.

\subsection{Problem Statement}

This study examines the perception of employees about their Bosses. It shall be investigated that whether the Boss is always right in respect of his or her attitude, ethical consideration and biasness.

\section{Hypothesis}

H1. The attitude of Manager as Leader regarding giving order has significant positive effect on the attitude of employees. 
$\mathrm{H} 2$. The role of Manager as Leader regarding Conflict Management has significant positive effect on the attitude of employees.

H3. The Belief that Manager as Leader has broad vision has significant positive effect on the attitude of employees.

H4. The Belief that a Manager as Leader is the Best Leader has significant positive effect on the attitude of employees

\section{LITERATURE REVIEW}

If boss cannot absorb those employees have skills to create a change than this does not mean that employees, in real, do not have those skills so the confidence level should be maintained. This study is based that what happens when boss posses un ethical behavior, behavior with injustice characteristics, gender difference biasness, favoritism, profit earner through injustice with employees, putting high work pressure on employees. There is common practice that whenever employees or labors are creating unethical environment in organization than this is the boss who can make and the environment ethical. But think when boss is himself or herself creator of unethical environment and employees are witnessed of those activities. Then this becomes very difficult for employees to decide whether to speak up or adopt silence to save their job and reputation in co workers. The objective of this study is to put light on the concept that it is not necessary that boss is always right, this concept is opposite of traditional belief that boss in any organization is always right. Many studies discuss regarding management and give reasons for un professionalism of bosses and provide techniques that how to survive in that situation because the concept there is same that boss in organization is the right person but this article conveys the message that employee should think out of box that it is not a universal truth that a boss cannot be wrong.

Knippen and Green (1996) concluded that on handling of criticism from the Boss. This article discusses about the techniques of handling criticism. it shows another side that it is not necessary that every time it is employees' fault for which criticism is made, but sometime the personal problems of Boss might disturb or even irritate the employees the nature for which it continuously pin point the employees without any proper reason. So employees should not lose their power and self confidence.

Banaji, Bazerman and Chugh (2003) investigated the ethical consideration of the Bosses. The results showed that Bosses were favored for ethical consideration, however, simultaneously the biasness was also observed significantly in their places. It can be observed that issues regarding the boss or management are not only now a problem but it is a problem from past but in past there was silence in employees and lack of supportive policies which can helped.

Mizruchi (1983) conducts study to show relation between board of directors and management where board of directors are bosses which believe that management should work under the frame work, but most of the time board of directors are not well aware of new techniques and strategies of business because basically board of directors are 
investors who have good knowledge about where to invest and how to invest but to get maximum profit from investment and to maintain a constant growth rate in companies management have better knowledge. But if Board of Directors is setting a frame work then it should be able to set those limits so that company can grow and if targets will not achieved then Chief Executive Officer can be expelled.

Senger (1971) made study based on ranking of subordinates by managers and the factors which support the ranking. Similarity in values is one of those major factors in rank a subordinate. Mostly this is noticed that managers give high priority to those who have most similar values and good communication level with managers and low ranking to those who have less similar values. The reason behind this having two sides that this favoritism can be bias or it can be the perception that if there is good communication level then it will be less distortion in flow of messages. This favoritism can lead the organization towards good communication but less productivity and every subordinate expect rational and bias ranking.

Thad (1996) investigated the feelings and reactions of subordinates when their Bosses crtiticised countinously. The findings suggests that continuous criticism can decrease productivity because when a person continuously pin you then it will effect on your mind, you think that what was the fault why the boss never like the performance and this discouragement effect on psychology which divert mind and decrease productivity because employee lose concentration and spend time to search out the reasons. Actually it is not necessary that when employees are to be criticized then there is mistake done by , but it can be naturally a boss has nature of criticism in real life he is as same in his personal life and to criticize people is in his nature boss have no confidence in you, your boss think that you cannot do anything in a proper way boss do not have similar values with you which leads to lack in communication.

Thad (1996) suggests five techniques which help out employees to handle that criticism and continue to improve productivity by not losing their attention at work place. It's good to be criticized from boss but if criticism goes at high level without any proper justification then it give negative impact on employees. It is not necessary that always employees are victims of bosses but managers can also be victims of their bosses. In hierarchy system managers have employees working under and this is rule that for those employees their boss is that manager. But what happen when bosses themselves open two roads for employees and make mystified that it should have more than one boss.

Green (1997) investigated on the ethical issues related to Bosses. The results discusses about the condition when boss is turning theft ear of employees to break the rules set by their manager. Reason behind this problem can be different, boss may lost trust on manager that manager can direct the employees in a right way, boss assume himself or herself as a problem decipher and want to solve every matter, boss can be a very conversational person and admire to communicate with people. There can be any reason for which that manager can suffer. Impact of this activity on whole department, employees and manager, that department as a whole will suffer because productivity of employees can decline due to diversify attention on more than one boss that whom 
to report ant whom to obey. Managers also feel lack of manage over employees. To protect the organization from entire affairs boss should wait if he or she is finding the manager and lead the employees that what problem or guidance is need should ask manager. If boss is not then this is manager's responsibility to stop this kind of unethical activity for the sake of employees and to keep a healthy environment of organization.

Hasan and Subhani ( 2012) suggests that usually in organizations there is a policy to keep recording activities of employees that whether employees are busy in office work or their own personal activities. But this policy is just to check the performance but when it is converted into desire of management / boss to record the employees then it has a mental effect on employees. Traditional way of monitoring is to monitor the employees through cameras and track the phone calls and employees should aware of this. But when instead of cameras their co-workers start recording that with whom employees are engage on calls etc then it creates the interference in employees' life and perception of un-easiness at work place merges. This un-easiness leads to employees (stress, mental illness, de motivation) at work place when one employees is interested in the matter of his or her co worker instead of paying attention on work, it create a political environment where one person is shifting the information of second one to the third one.

This kind of monitoring is reason of decline in wish to be there at work place and this wish leads to low productivity and stress in life and job. This article conveys the message that if policies are made then it is very necessary to follow those policies in right way and formal way at the at the moment those policies change in any indirect way of doing or performing employees become the reason of going down of organization and this is whole can be maintained by boss but unfortunately, the bosses who involve in giving birth to this environment because Bosses want to record each and every activity but via an indirect way.

Employees are main assets for organization and new concept is here that salary of an employee in account department is in liability form on company but the actual name and form of that salary is investment for present as well for future on assets. To retain employees it is necessary to get constancy of employees.

Kaityan (2011) investigated the perception of employees' loyality. Conclusion suggests that Loyalty is very vital because lack of this element can create decline in productivity and increase in turnover. American corporate dismisses the employees without giving any warning and this sudden situation is giving the shocking news. Due to this management's activity employees lost trust on management and employees have alarm in their mind that any time employees can be called from management and get order to leave the place. This insecurity creates disloyalty and hence employees do not feel as a part of organization. Overall survey showed that employees feel that the loyalty of employees for company is more than the management loyalty, and on the other hand management's perception is that Management is fully loyal to their employees." this variance in view of management and employees show the sever connections in thinking which is wrong measurement of employees loyalty. Management make castle in the air that their employees are loyal towards their work but it is not made due to 
management's not expected activities.

This is management responsibility to maintain the ethical environment in organization but boss is not paying attention and due to this employees will suffer. Instead of thinking the strategies of giving better performance than previous it may be thought on techniques that how employees may be protected from unethical environment. To increase the growth rate is not only a boss responsibility but to make an environment where company can grow with growing the social responsibility.

Gavin (2005) made study to discuss all about the relation between Trust on management and Performance of employees. The center of attention of the study is not only the productivity but he has also shows that if employees have trust on their management then it creates focus attention that leads to good performance in organization. If management is in touch with employees on daily basis, have trust and also share the tactics of decision making then it helps employees in giving their best at work place.

G Patterson (2003) made study and take survey of employees of different organizations. The result showed that the more satisfied the worker is the more productive organization is. The study focuses on the impact of attitude of employees on the profit of organization and employee compare the prior and after profit of organization when organization work on attitude of employees because study shows that attitude plays important role in human satisfaction at job place.

Brusman (2009) suggest that an employee who is promoted to higher level it is very necessary to change all bad habits. After a time it is very necessary for us to accept the Change. The best bosses are those who are truthful, empathic and who are unite with employees and the worst bosses are outlying, intricate and supercilious.

\section{RESEARCH METHODOLOGY}

\subsection{Method of Data Collection}

The primary source of data collection has been used directly collected from the professionals using the questionnaire. The respondents of the survey are middle and operation level employees of various companies including Banking, Manufacturing and Financial houses. A well-prepared questionnaire has been designed which has been provided to the responded that fills this questionnaire and return it back. The questioner is close ended with 5 five options i.e. Strongly Disagree, Disagree, Neutral, Agree and Strongly Disagree. Each option is assigned a coded value which shall be calculated in the one sample test. The number starts from strongly disagree, which has been given value: 1 then value 2 is given to disagree, 3 for Neutral, 4 for agree and 5 for strongly agree.

\subsection{Sampling technique}

Random sampling is used as sampling technique to collect the data. A sample of 500 persons have been selected on random basis from the population of Karachi, Pakistan, where were provided well-designed questionnaire. 


\subsection{Sample Size}

A sample of 500 respondents has been used for the analysis, belonging to different professions such as Teaching, Corporate Professionals etc belonging to various Industrial sectors in Pakistan.

\subsection{Statistical Technique}

The empirical analysis is based on the application of OLS estimation. The reliability of the data has been tested by applying the reliability statistics such as Cronbach's Alpha.

\section{RESULTS AND INTERPRETATIONS}

Findings and Interpretation of the results

For Primary Data collection such as by mean of Questionnaire the reliability test is applied to test reliability of the collected data.

For instances as shown in table 1 (see appendix)

For the reliability the value of Cronbach's Alpha should be greater than 0.5 , here it is 0.782 which shows that the

In case we have developed a framework based on OLS estimations we can apply Regression.

Since the ANOVA is significant as shown in table 2 (see appendix), hence now we can proceed to the results of Regression Model.

The results of table 3 (see appendix) suggest that subordinates consider the orders of Boss as important and they don't show their anger upon it. The model estimates suggests that in the time of conflict the role of Boss is of crucial important. The subordinates deem it reasonable that their Boss can be the best option for conflict management. Ultimately the subordinates believe that Boss may be their best boss. However the subordinates did not agree that Boss has big visions.

The survey result shows that attitude of Manager as leader has favorable impact on the development of organizational culture and the Manager as leader creates an environment where organizational goals are given top priority. Likewise respondents agree that the Manager as leader provides pleasant environment where you feel you get work-family balance life and that the attitude of Manager as leader gives feelings of strong motivation for your assigned task to his or her subordinates. Besides, the attitude of Manager as leader gives his or her feelings of strong motivation for your assigned task and that the attitude of Manager as leader has positive role in achieving targets of his or her subordinates. 


\section{Summary of the Survey}

The respondents agree that people agree that the Manager as leader always appreciates innovative ideas from his or her subordinates. Moreover, the respondents believe that their Manager as leader does not Forces employee to do unethical deeds which gives benefit to their Manager as leader than their organization. Likewise the respondents believe that respondent believes that their Manager as leader gives unbiased recommendations for performance evolution irrespective his or her likes and dislikes.

Finally the respondents believe that their Manager as leader does not give preference to achieve his or her personal objective over organizational objectives and further the respondent believes that their Manager as leader behaves impartially while resolving the conflict and supports only to the deserving party rather than his or her favorite party.

\section{DISCUSSIONS, CONCLUSION AND IMPLICATIONS}

\subsection{Discussion}

I $\mathrm{n}$ a survey of 500 respondents based on a comprehensive questionnaire on Licker scale. The respondents show their positive concern regarding the attitude of their Manager as leader at work. The respondents Believe that their Manager as leader usually response with positive and supportive attitude which help in achieving the objectives. The positive attitude of Manager as leader plays vital role in creating pleasant organizational culture and environment. Further, the respondent show their consent that behavior of their Manager as leaderes is impartial and unbiased during conflict resolution and submission of recommendation for evaluation etc.. The respondents appear to highly appreciate that their Manager as leaders prefer organizational objectives over their personal objectives and their Manager as leaders do not force to do any unethical deed to benefit.

\subsection{Conclusion}

The analysis of the survey shows very interesting results. The respondents believe that the attitude of their Manager as leader plays very crucial role in the organizational performance and that of organizational success. The respondents show their consent that their Manager as leader has favorable impact on the development of organizational culture and that the attitude of Manager as leader gives his or her feelings of strong motivation for assigned task of his or her subordinates. Further, the attitude of Manager as leader has positively affected the work-performance of his or her subordinates. It was also agreed by the respondents that the attitude of Manager as leader has positive role in achieving targets of his or her subordinates. The result indicates that most of the respondents believe that attitude of their Manager as leader is favorable and supportive for achieving their objectives as well as organizational objectives. It has been supported by the respondent that their Manager as leader appreciates their Innovative solutions and proposals for organizational matters, which indicates that Manager as leader also posses one of the best quality of leadership that he or she does not want to 
let his or her subordinates down.

With respective to forcefully unethical deeds, the respondents believe that their Manager as leaders do not force employee to do any unethical deeds that benefit to the Manager as leaders only. This favors that a Manager as leader tries every best to protect the interest of the organization and that Manager as leader avoids their conflict of interest with organizational objectives. The respondents believe that their Manager as leaders do not prefer his or her personal objectives over the organizational objectives.

With respect for favoritism and Biasness, the respondent showed positive response towards their Manager as leaders.

The respondents believe that Manager as leader gives unbiased recommendations for performance evolution for the subordinates but he or she does not favor to those who do flattery rather than to those subordinates who really deserve it. In case of conflict resolution, the Manager as leader makes impartial decision and judgment and he or she does not support to his or her favorite subordinates.

\subsection{Implications}

The result shows that attitude of a Manager as leader has very significant effect over organizational environment and organizational culture. In addition to attitude of Manager as leader, ethical consideration and equality and justice build the foundation stone of organizational culture as well as organizational success. The findings of this study suggest that Manager as leader has positive and supportive role in organizational success.

\section{REFERENCES}

Brusman, D. M. (2009). Good Boss, Bad Boss: 20 Bad Habits Leaders Should Stop Doing Now. Helping Companies Assess, Select, Coach \& Retain Emotionally Intellegent People , 3, 1-4.

Fakhar Shahzad, R. A. (2012). Impact of Organizational Culture on Organizational Performance. Interdisciplinary journal of contemporary research in business $, 3,45-54$.

Fassin, Y. (2005). The reasons behind non-ethical behaviour in business and entrepreneurship. Journal of business ethics, 60, 256-279.

Gavin, R. C. (2005 ). trust in managment and performance. Academy of journal management , 48, 874-888.

Green, j. T. (1996). How to get feedback from your boss. journal of workplace today , 8, 13-16. 
18.

Hasan, D. S., \& Subhani, M. I. (2012). Top management's snooping: Is sneaking over employees' productivity and job commitment a wise approach? African Journal of Business Management, 35691, 1-11.

Mahzarin R.banaji, M. H. (2003). How Unethical You are. Harward Business Review , 56-64.

Malcolm G Patterson, M. A. (2003). Impact of People Management Practices on Business Performance (Vol. 4). London, United Kingdom: institute of personnel and development.

Mary Uhl-Bien, M. K. (2007). Being Ethical When the Boss Is Not. managment department publication, 36, 187-201.

Mayhew, R. (n.d.). Importance of Employee Performance in Business Organizations. Retrieved from http://smallbusiness.chron.com/importance-employeeperformance-business-organizations-1967.html.

S.Mizruchi. (2003). Who control whom?an examination of relation between managment and BOD. The academy of managment review , 8, 212-228.

Senger, J. (1971). Managers' Perceptions of Subordinates' Competence As a Function of Personal Value Orientations. Academy of Management Journal , 14, 415423.

Udegbe, D. O. (2004). Relationship, Gender in the Boss-Subordinate. Journal of Organizational Behavior, 25, 515-525. 


\section{Appendix}

\section{Table 1: Reliability Statistics}

\begin{tabular}{|l|l|}
\hline Cronbach's Alpha & N of Items \\
\hline 0.782 & 17 \\
\hline
\end{tabular}

Table 2 ANOVA

\begin{tabular}{|l|l|l|l|l|l|}
\hline & Sum of Squares & df & Mean Square & F & Sig. \\
\hline Regression & 92.669 & 4 & 23.167 & 34.657 & .000 \\
\hline Residual & 308.834 & 462 & .668 & & \\
\hline Total & 401.503 & 466 & & & \\
\hline
\end{tabular}

\section{Table 3 Regression Model}

\begin{tabular}{|c|c|c|c|c|c|}
\hline & \multicolumn{2}{|c|}{$\begin{array}{l}\text { Unstandardized } \\
\text { Coefficients }\end{array}$} & \multirow{2}{*}{$\begin{array}{l}\text { Standardized } \\
\text { Coefficients } \\
\text { Beta }\end{array}$} & \multirow[b]{2}{*}{$\mathrm{t}$} & \multirow[b]{2}{*}{ Sig. } \\
\hline & B & Std. Error & & & \\
\hline (Constant) & .425 & .121 & & 3.520 & .000 \\
\hline Orders of Manager as Leader & .172 & .036 & .212 & 4.853 & .000 \\
\hline $\begin{array}{l}\text { Manager as Leader for Conflict } \\
\text { Management }\end{array}$ & .166 & .030 & .232 & 5.524 & .000 \\
\hline Vision of Manager as Leader & -.001 & .031 & -.001 & -.018 & .986 \\
\hline Boss as best leader & .369 & .059 & .264 & 1.273 & .312 \\
\hline
\end{tabular}

